\title{
Astrocytes Are Primed by Chronic Neurodegeneration to Produce Exaggerated Chemokine and Cell Infiltration Responses to Acute Stimulation with the Cytokines IL-1 $\beta$ and TNF- $\alpha$
}

\author{
Edel Hennessy, @Éadaoin W. Griffin, and @Colm Cunningham \\ Trinity College Institute of Neuroscience, School of Biochemistry \& Immunology, Trinity College Dublin, Dublin 2, Ireland
}

\begin{abstract}
Microgliosis and astrogliosis are standard pathological features of neurodegenerative disease. Microglia are primed by chronic neurodegeneration such that toll-like receptor agonists, such as LPS, drive exaggerated cytokine responses on this background. However, sterile inflammatory insults are more common than direct CNS infection in the degenerating brain and these insults drive robust IL- $1 \beta$ and TNF- $\alpha$ responses. It is unclear whether these pro-inflammatory cytokines can directly induce exaggerated responses in the degenerating brain. We hypothesized that glial cells in the hippocampus of animals with chronic neurodegenerative disease (ME7 prion disease) would display exaggerated responses to central cytokine challenges. TNF- $\alpha$ or IL- $1 \beta$ were administered intrahippocampally to ME7-inoculated mice and normal brain homogenate-injected (NBH) controls. Both IL- $1 \beta$ and TNF- $\alpha$ produced much more robust IL- $1 \beta$ synthesis in ME7 than in NBH animals and this occurred exclusively in microglia. However, there was strong nuclear localization of the $\mathrm{NF} \kappa \mathrm{B}$ subunit $\mathrm{p} 65$ in the astrocyte population, associated with marked astrocytic synthesis of the chemokines CXCL1 and CCL2 in response to both cytokine challenges in ME7 animals. Conversely, very limited expression of these chemokines was apparent in NBH animals similarly challenged. Thus, astrocytes are primed in the degenerating brain to produce exaggerated chemokine responses to acute stimulation with pro-inflammatory cytokines. Furthermore, this results in markedly increased neutrophil, T-cell, and monocyte infiltration in the diseased brain. These data have significant implications for acute sterile inflammatory insults such as stroke and traumatic brain injury occurring on a background of aging or neurodegeneration.
\end{abstract}

Key words: astrocyte; chemokine; cytokine; microglia; neurodegeneration; neuroinflammation

\section{Introduction}

Microgliosis and astrogliosis are hallmarks of neurodegeneration. Microglia in the degenerating brain show a "primed" response to LPS stimulation (Cunningham et al., 2005). When first described, we used the term priming to convey that microglia responded to acute stimulation with LPS by producing exaggerated IL- $1 \beta$ response and robust synthesis of inducible nitric oxide synthase, similar to the original description of peripheral macrophage priming (Pace et al., 1983). Microglial priming was first

Received April 18, 2014; revised March 12, 2015; accepted April 5, 2015.

Author contributions: C.C. designed research; E.H., E.W.G., and C.C. performed research; E.H. and C.C. analyzed data; E.H., E.W.G. and C.C. wrote the paper.

This work was supported by The Wellcome Trust and E.H. was supported by a Trinity College Dublin Research Studentship. We acknowledge the gift of the Mc21 anti CCR2 antibody from Steffen Jung, Weizmann Institute of Science, Israel, and the MBS-1 neutrophil antibody from Daniel Anthony, Oxford, UK. We thank Hugh Perry and Diego Gómez-Nicola for helpful discussions and Gavin MacManus for technical assistance with confocal microscopy. The authors declare no competing financial interests.

This article is freely available online through the J Neurosci Author Open Choice option.

Correspondence should be addressed to Colm Cunningham, Trinity College Institute of Neuroscience, School of Biochemistry \& Immunology, Trinity College Dublin, Dublin 2 Ireland. E-mail: colm.cunningham@tcd.ie.

DOI:10.1523/JNEUROSCI.2745-14.2015

Copyright @ 2015 Hennessy et al.

This is an Open Access article distributed under the terms of the Creative Commons Attribution License Creative Commons Attribution 4.0 International, which permits unrestricted use, distribution and reproduction in any medium provided that the original work is properly attributed. demonstrated in the ME7 model of prion disease but has been replicated in multiple models of brain pathology including aging (Chen et al., 2008), Tg2576 model of AD (Sly et al., 2001), and models of PD (Pott Godoy et al., 2008). However, there is no specific evidence that primed microglia have a discrete molecular identity. Rather, one may use the term primed to describe the propensity of a particular cell type to make an exaggerated response to a typical stimulus; therefore, this terminology may also be applied to other CNS cell types in situations where they show exaggerated production of secretory products typical to that cell population. In the case of primed microglia they show an exaggerated IL-1/iNOS response to LPS (Cunningham et al., 2005). However, all prior studies of microglial priming examine responses to LPS, the appearance of which inside the CNS is a rare pathological event. Sterile inflammatory insults such as stroke are very common in the aging population and significantly increase IL- $1 \beta$ and TNF- $\alpha$ levels, leading to chemokine synthesis and inflammatory cell recruitment to the brain parenchyma. It is unclear whether microglia in the degenerating brain show differential responses to sterile inflammatory insults such as the pro-inflammatory cytokines IL- $1 \beta$ and TNF- $\alpha$ and we wished to investigate this in the current study.

It is also of considerable interest to interrogate whether astrocytes may also be primed to show exaggerated responses to typical 
stimulators of astrocyte activation. These cells support metabolic functions of neurons and maintain CNS homeostasis but they also have immune functions in the CNS. Stimuli such as $A \beta$, Escherichia coli, Poly I:C, LPS, and Flagellin induce production of chemokines such as CCL2 and CXCL1 in astrocytes in vitro (Kim et al., 2005; McKimmie and Graham, 2010) and both TNF- $\alpha$ and IL- $1 \beta$ can also induce astrocyte CCL 2 and CXCL1 in vitro (Thompson and Van Eldik, 2009; An et al., 2011; Choi et al., 2011; Lee et al., 2012).

Thus we hypothesized that both microglia and astrocytes in the degenerating brain may respond in an exaggerated manner to acute cytokine stimulation and that chemokine synthesis might be a significant feature of any such exaggerated response. To investigate the reactions of both microglial and astrocytic cells to acutely elevated cytokines, we administered intrahippocampal TNF- $\alpha$ or IL- $1 \beta$ to normal and ME7 prion-diseased animals and examined the cytokine and chemokine expression at $2 \mathrm{~h}$ post challenge. To investigate the cellular consequences of acute cytokine and chemokine secretion we examined neutrophil infiltration at $24 \mathrm{~h}$ and immune cell infiltration at $72 \mathrm{~h}$, predicting more robust infiltration in animals with prior disease. It is reported that IL-1 $\beta$ induces CXCL1 and neutrophil infiltration (Campbell et al., 2002) and TNF- $\alpha$ induces CCL2 and monocyte infiltration (Campbell et al., 2005) and that these pathways only cross over to a limited extent (Schnell et al., 1999; Blond et al., 2002). However, experiments on the extent, and the cell-type selectivity, of immune cell infiltration after intracerebral inflammatory insult have generally been performed in young healthy animals. The degree to which inflammatory cell infiltration remains tightly regulated during acute insults to the degenerating brain has been little studied; therefore, we examined patterns of immune cell infiltration after TNF- $\alpha$ or IL- $1 \beta$ challenge in animals with existing neurodegeneration (ME7), compared with normal healthy animals.

\section{Materials and Methods}

Animals and stereotaxic surgery. Female C57BL/6 mice (Harlan) were housed in cages of five at $21^{\circ} \mathrm{C}$ with a $12 \mathrm{~h}$ light/dark cycle. Food and water access was ad libitum. Mice were anesthetized intraperitoneally with Avertin $\left(50 \% \mathrm{w} / \mathrm{v}\right.$ in tertiary amyl alcohol, diluted $1: 40$ in $\mathrm{H}_{2} \mathrm{O}$; $20 \mathrm{ml} / \mathrm{kg}$, i.p.; Sigma) and positioned in a stereotaxic frame (Kopf Instruments). Holes were drilled at $-2.0 \mathrm{~mm}$ (anteroposterior) and $\pm 1.6 \mathrm{~mm}$ (lateral, either side of the midline) from bregma, and $1 \mu \mathrm{l} 10 \% \mathrm{w} / \mathrm{v}$ ME7-infected C57BL/6 brain homogenate was injected into the hippocampus using a Hamilton microsyringe to a depth of $-1.7 \mathrm{~mm}$. The needle was left in situ for $2 \mathrm{~min}$ before slow withdrawal. Control animals were administered $1 \mu \mathrm{l} 10 \% \mathrm{w} / \mathrm{v}$ normal brain homogenate (NBH). Mice were placed in an incubator at $\sim 25^{\circ} \mathrm{C}$ for recovery. When returned to their home cage they were administered sucrose $(5 \% \mathrm{w} / \mathrm{v})$ and carprofen $(0.05 \% \mathrm{v} / \mathrm{v}$; Rimadyl; Pfizer, $)$ in their drinking water for $2 \mathrm{~d}$ postsurgery. Animals were monitored for recovery from surgery. All animal experimentation was performed under a license granted by the Minister for Health and Children, Ireland, with approval from the local ethical committee and in compliance with the Cruelty to Animals Act, 1876 and the European Community Directive, 86/609/EEC. Every effort was made to minimize stress to the animals.

At 18 weeks post inoculation with ME7 or $\mathrm{NBH}$, animals were anesthetized once again and positioned in a stereotaxic frame (Kopf Instruments). Unilateral (right side) $1 \mu \mathrm{l}$ injections were made into the hippocampus at the same coordinates as before, using a pulled glass microcapillary (Sigma). In initial experiments control animals were sham operated, without insertion of microcapillary or injection of vehicle solution, since the primed microglial state is highly susceptible even to minor acute stimulation, and we predicted glial responses even to the small local injury of insertion of a microcapillary. Since we aimed to demonstrate the phenotypic switching of microglial/astroglial cells upon cytokine stimulation, it was important to observe glial cells and cytokine/ chemokine expression in the unchallenged ME7 brain. However, for consistency with cytokine injection experiments we also performed saline-injected controls and compared cytokine-injected animals to both sham-operated and saline-injected controls for cytokine/chemokine synthesis at $2 \mathrm{~h}$ post insult. For studies on cytokine-induced mRNA transcription all control animals were injected with saline and perfused $2 \mathrm{~h}$ post challenge. For cell-infiltration studies, we compared cytokine-injected animals to saline-injected animals at $24 \mathrm{~h}$ post injection (for neutrophils) and at $72 \mathrm{~h}$ for macrophage infiltration. TNF- $\alpha$ (PeproTech) was used at $300 \mathrm{ng} / \mu$ land IL- $1 \beta$ (R\&D Systems) was used at $10 \mathrm{ng} / \mu \mathrm{l}$. Both were prepared using sterile saline (Sigma). Both TNF- $\alpha$ and IL- $1 \beta$ were shown to have endotoxin units beneath the Food and Drug Administration standard for endotoxin-free injectable drugs. An anti-CCR2 antibody (hybridoma supernatant; Mc21; Bruhl et al., 2007) was used to deplete circulating CCR $2^{+}$monocytes. Two hundred microliters of Mc21 supernatant was administered intraperitoneally $14 \mathrm{~h}$ before and again $24 \mathrm{~h}$ after intrahippocampal TNF- $\alpha$ injection to examine macrophage infiltration at $72 \mathrm{~h}$ post TNF- $\alpha$. This is sufficient time to deplete circulating macrophages (Bruhl et al., 2007; Yona et al., 2013).

Tissue preparation. Animals for mRNA analysis of cytokine-induced transcriptional changes were terminally anesthetized with sodium pentobarbital at $2 \mathrm{~h}$ post challenge (Euthatal; Merial Animal Health) and rapidly transcardially perfused with heparinized saline. A tissue punch containing the diseased/normal hippocampus was taken at the appropriate anterior-posterior coordinates from bregma. Tissue was snap frozen in liquid nitrogen and was stored at $-80^{\circ} \mathrm{C}$ until use. Animals for immunohistochemical examination were terminally anesthetized with sodium pentobarbital (Euthatal; Merial Animal Health) and transcardially perfused with heparinized saline for $\sim 3$ min followed by $10 \%$ neutral buffered formalin (Sigma) for $\sim 15 \mathrm{~min}$. Brains were postfixed in formalin and then embedded in paraffin wax. Coronal sections $(10 \mu \mathrm{m})$ were cut on a Leica RM2235 Rotary Microtome (Leica Microsystems) at the level of the hippocampus and floated onto electrostatically charged slides (Menzel-Glaser) and dried at $37^{\circ} \mathrm{C}$ overnight.

Immunohistochemistry. Sections were labeled with IBA-1, 1/2000, ab5076 (Abcam); IL-1 $\beta, 1 / 50,500-P 51$ (PeproTech); TNF- $\alpha, 1 / 1000$, part 840143 of DY410 (R\&D Systems); P65, 1/1000, sc-8008 (Santa Cruz Biotechnology); CCL2, 1/100, part 840288 of DY479 (R\&D Systems); GFAP, 1/2000, Z0334 (Dako Cytomation); CXCL1, 1/50, AF-453-NA (R\&D Systems); CD68, 1/50, MCA1957, (AbDSerotec); CD3, 1/250, A0452 (Dako Cytomation); Pu.1, 1/400, \#2266 (Cell Signaling Technology); and MBS-1, 1/5000 (a gift from Daniel Anthony, Oxford, UK). Sections were pretreated with $1 \% \mathrm{H}_{2} \mathrm{O}_{2} /$ methanol (20 min); microwaved in citrate buffer, $\mathrm{pH} 6$, for $2 \times 5 \mathrm{~min}$; and preblocked with the appropriate serum. $\mathrm{CD} 68$ sections were pretreated with $0.5 \%$ Pronase in $\mathrm{dH}_{2} \mathrm{O}$ for 20 min before block. IBA-1 and CCL2 sections were pretreated with $0.04 \%$ pepsin in $0.1 \mathrm{M} \mathrm{HCl}$ for 20 min before blocking. P65 and Pu.1 sections were pretreated with $1 \%$ Triton in PBS for 15 and 20 min, respectively, before blocking. $\mathrm{CD} 3$ sections were pretreated with both pepsin and Triton before block. Thereafter the ABC method was used as previously described (Cunningham et al., 2005) with peroxidase as enzyme, 3,3'-diaminobenzidine as chromogen, and $\mathrm{H}_{2} \mathrm{O}_{2}$ as substrate. Slides were counterstained using hematoxylin (VWR International). Immunolabeling for TNF- $\alpha$, CCL2, and CXCL1 antibodies was validated by omission of primary antibodies, compared with labeling from unrelated primary antibodies from the same species and, in particular, by preabsorption with the relevant recombinant cytokines. Antibodies were incubated with a molar excess of recombinant cytokine $1 \mathrm{~h}$ before incubation with the tissue. TNF- $\alpha$, CCL2, and CXCL- 1 antibodies were diluted into recombinant cytokine/chemokine standards to give a molar excess of recombinant cytokine:antibody of $\sim 1.5$. Labeling with preabsorbed antibodies is shown in Figure $1 n$ (inset, TNF- $\alpha$ ) and Figure $5 b$ (inset, CCL2) and $d$ (inset, CXCL1).

Confocal microscopy. Pretreatments, primary antibodies, and secondary fluorophores (Alexa Fluor; Life Technologies) were applied in a sequential manner for all double labeling. Secondaries used were as follows: IBA-1, 594 donkey anti-goat; IL-1 $\beta, 488$ goat anti-rabbit; P65, 633 goat anti-mouse; GFAP, 488 goat anti-rabbit; CCL2, 594 donkey anti-goat; 
CXCL1, 594 donkey anti-goat. Hoechst 33258 was applied at $0.5 \mu \mathrm{g} / \mathrm{ml}$ for $10 \mathrm{~min}$. Prolong Gold (Sigma) was used as an aqueous mounting solution. Slides were allowed to dry overnight before visualization on an Olympus FV 1000 confocal microscope using FV10 ASW 3.0 software. Images were captured using sequential excitation of the fluorophores. Images were captured at 1024 pixels at $10 \mu$ s per pixel. The Kalman filter was applied to each image. Most images were obtained at $60 \times$ oil with optional digital zoom (NA 1.35). $Z$-stack images represent a single optical section from multiple sections in the $z$-plane $(6-12 ; 1024 \times 1024$ pixels, spaced $0.8-1.2 \mu \mathrm{m}$ in the $z$-plane).

Immunohistochemical quantification. At $24 \mathrm{~h}$ MBS-1-positive neutrophils were photographed at $5 \times$ magnification and quantified in an area of $4.64 \mathrm{~mm}^{2}$ centered on the injected dorsal hippocampus. In ImageJ (NIH) MBS-1-positive cells were identified using 16-bit thresholded images and quantified using the Analyze Particles function. Particle size was set at 30-300 pixels with a sphericity of $0.7-1.00$. At $72 \mathrm{~h} \mathrm{CD} 3$ and MBS-1-positive cells were much fewer and were manually counted. The region counted was limited to the injected hippocampus in sections matched for anterior-posterior position. Pu.1-positive macrophages/ microglia were quantified from $20 \times$ images proximal to the needle track. In ImageJ (NIH) Pu.1-positive cells were identified using 16-bit thresholded images and quantified using the Analyze Particles function. Particle size was set at $>30$ pixels with a sphericity of $0.5-1.00$.

RNA extraction and quantitative PCR. Total RNA was isolated using the RNeasy Plus Mini method (Qiagen) as per the manufacturer's instructions. To ensure complete DNA elimination from the columnbound RNA, an on-column DNase step was performed. The RNA yield and quality of each sample was quantified based on optical density using the NanoDrop'ND-1000 UV-Vis spectrophotometer (Thermo Fisher Scientific). cDNA synthesis was performed using a High Capacity cDNA Reverse Transcriptase Kit (Applied Biosystems). cDNA was stored at $-20^{\circ} \mathrm{C}$ until use in RT-PCR. All primer and probe sets were designed using Applied Biosystems Primer Express software and amplified a single sequence of the correct amplicon size, as verified by SDS-PAGE. Where no probe sequence is shown, the DNA binding dye SYBR green was used in its place. Primer pair/probe sequences are shown in Table 1. Samples for RT-PCR were run in duplicate and contained $12.5 \mu \mathrm{l}$ FastStart Universal Probe Master mix (Roche); $0.5 \mu$ l of each of the forward primer (10 $\mu \mathrm{M})$, reverse primer $(10 \mu \mathrm{M})$, and probe $(10 \mu \mathrm{M})$; and $10 \mu \mathrm{l}$ RNase-free water. All PCR was performed in a StepOne Real-Time PCR system (Applied Biosystems) under the cycling conditions: $95^{\circ} \mathrm{C}$ for $10 \mathrm{~min}$ followed by $95^{\circ} \mathrm{C}$ for $10 \mathrm{~s}$ and $60^{\circ} \mathrm{C}$ for $30 \mathrm{~s}$ for 40 cycles. Quantification was achieved by exploiting the relative quantitation method, using cDNA from LPS-injected mouse brain as a standard expressing all genes of interest and fourfold serial dilutions of this cDNA to construct a linear standard curve relating cycle threshold values to relative concentrations. This method has been described in detail previously (Cunningham et al., 2005). Gene expression data were normalized to the housekeeping gene GAPDH.

Statistics. All data were analyzed by two-way ANOVA with disease and treatment as between-subjects factors. Selected pairwise comparisons were made by Bonferroni post hoc tests after significant effects by ANOVA.

\section{Results}

\section{Microglial priming}

Microglial labeling with IBA- 1 was examined $2 \mathrm{~h}$ after IL- $1 \beta$ and TNF- $\alpha$ challenges. There were no apparent morphological alterations in microglia in normal animals $2 \mathrm{~h}$ post cytokine challenge (Fig. $1 a-c$ ). As previously described microgliosis occurs in ME7 animals, increasing microglial numbers and altering morphology (Fig. 1, compare $a-c, d-f$ ). Using the higher power images $g-i$, it is possible to discern a robust alteration in microglial morphology occurring in ME7 animals following cytokine challenge. Following both cytokine challenges, microglia in ME7 animals display a more condensed cell body with retracted processes compared with the less dense cell body and more ramified processes displayed in vehicle-injected ME7 animals (Fig. $1 g$ ).
Table 1. Quantitative PCR primer and probe sequences

\begin{tabular}{|c|c|c|}
\hline Transcript & Oligo (probes: FAM) & Oligonucleotide sequences $\left(5^{\prime}-3^{\prime}\right)$ \\
\hline \multirow[t]{3}{*}{ IL-1 $\beta$} & Forward & GCACACCCACCCTGCA \\
\hline & Reverse & АССGCTTTTCСАTСTCTTCTT \\
\hline & Probe & TGGAGAGTCTGGATCCCAAGCAATACCC \\
\hline \multirow[t]{3}{*}{ TNF-a } & Forward & CTCCAGGCGGTGCCTATG \\
\hline & Reverse & GGGCCATAGAACTGATGAGAGG \\
\hline & Probe & TCAGCCTCTTCTCATTCCTGCTTGTGG \\
\hline \multirow[t]{3}{*}{ CCL2 } & Forward & GTTGGCTCAGCCAGATGCA \\
\hline & Reverse & AGCCTACTCATTGGGATCATCTTG \\
\hline & Probe & TTAACGCCCCACTCACCTGCTGCTACT \\
\hline \multirow[t]{3}{*}{ CXCL1 } & Forward & CACCCAAACCGAAGTCATAGC \\
\hline & Reverse & AATTTTCTGAACCAAGGGAGCTT \\
\hline & Probe & TCGCGAGGCTTGCCTTGACCC \\
\hline \multirow[t]{3}{*}{ RANTES } & Forward & GCAGTCGTGTTTGTCACTCGAA \\
\hline & Reverse & GATGTATTCTTGAACCCACTTCTTCTC \\
\hline & Probe & AACCGCCAAGTGTGTGCCAACCC \\
\hline \multirow[t]{3}{*}{ CXCL10 } & Forward & GCCGTCATTTTCTGCCTCAT \\
\hline & Reverse & GCTTCCCTATGGCCCTCATT \\
\hline & Probe & TCTCGCAAGGACGGTCCGCTG \\
\hline \multirow[t]{3}{*}{ PTX3 } & Forward & ACAACGAAATAGACAATGGACTTCAT \\
\hline & Reverse & CTGGCGGCAGTCGCA \\
\hline & Probe & CCACCGAGGACCCCACGCC \\
\hline \multirow[t]{2}{*}{ GFAP } & Forward & CTCCAACCTCCAGATCCGAG \\
\hline & Reverse & TCCACAGTCTTTACCAGATGT \\
\hline \multirow[t]{2}{*}{ STEAP4 } & Forward & TGCAAGCCGGCAGGTGTTTGT \\
\hline & Reverse & TCCAGTGGGGTGAGCCCAAGA \\
\hline
\end{tabular}

Where no probe is shown SYBR green assays were used.

These sections were also labeled with antibodies against IL- $1 \beta$ or TNF- $\alpha$. The injected TNF- $\alpha$ is apparent in the hippocampus of both NBH (Fig. 1l) and ME7 (Fig. 1o), because of the relatively large amount injected (300 ng), and it is not possible to establish whether there is any de novo TNF- $\alpha$ production in these animals. Figure $1, k$ and $n$, show that intrahippocampal IL- $1 \beta$ does not induce any TNF- $\alpha$ protein at $2 \mathrm{~h}$ post injection.

Unlike TNF- $\alpha$, injected IL- $1 \beta$ could not be observed due to the small amounts of this potent cytokine injected $(10 \mathrm{ng})$. We did not find reliably detectable IL- $1 \beta$ production in $\mathrm{NBH}$ animals, whether saline injected or cytokine injected (Fig. 1p-r). Vehicle-injected ME7 animal(s) show a small amount of detectable IL-1 $\beta$ adjacent to the needle track; however, both IL-1 $\beta$ (Fig. 1t) and TNF- $\alpha$ (Fig. $1 u$ ) robustly induce IL- $1 \beta$ in ME7 animals at $2 \mathrm{~h}$ post challenge. Without exception, the morphology of IL- $1 \beta$-positive cells was microglial. Bright-field microscopy was sufficient to discern IL- $1 \beta$ produced exclusively by cells with branched processes and small elongated nuclei (microglial) alongside large, rounded astrocytic nuclei devoid of IL-1 $\beta$ protein labeling (Fig. $1 u$, inset). Double labeling was performed for the microglial marker IBA- 1 and IL- $1 \beta$ following both challenges to confirm this observation. Figure 1 III shows colocalization of IL-1 $\beta$ production (green) with IBA-1 (red) following IL- $1 \beta$ challenge in ME7. Figure 1 VI shows colocalization of IL- $1 \beta$ production with IBA- 1 following TNF- $\alpha$ challenge in ME7. Thus these microglia are primed to produce exaggerated IL- $1 \beta$ production upon challenge with either IL- $1 \beta$ or TNF- $\alpha$. Furthermore, they show evidence of morphological change as soon as $2 \mathrm{~h}$ post cytokine challenge.

\section{Astroglial activation}

Based on the well described activation of NF $\kappa$ B by IL- $1 \beta$ and TNF- $\alpha$, we examined the 655 subunit of NF $\kappa$ B. Nuclear localization of $\mathrm{p} 65$ indicates activation of $\mathrm{NF} \kappa \mathrm{B}$ and will generally lead to initiation of transcription of NF $\kappa \mathrm{B}$-dependent genes in that cell. 

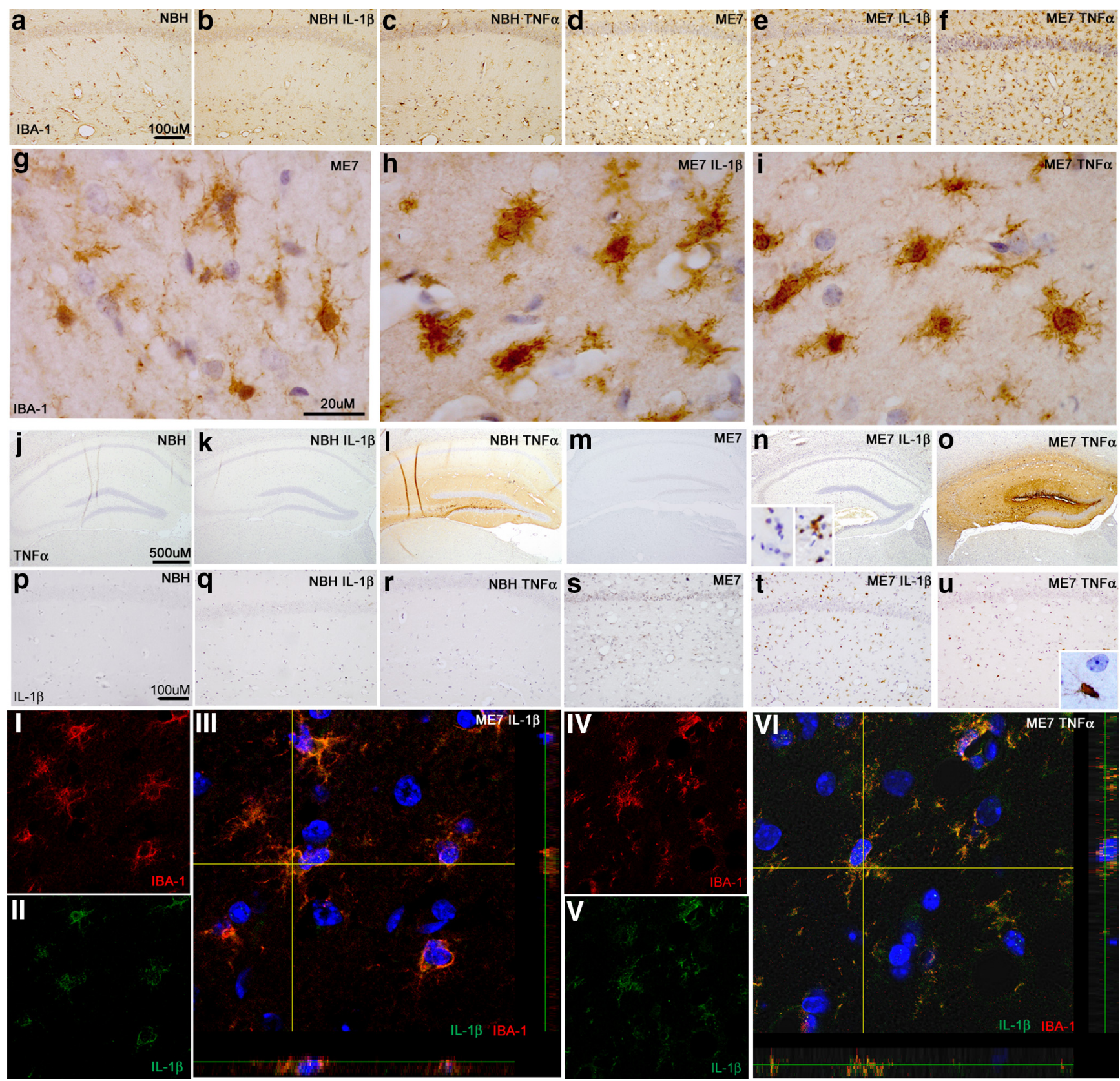

Figure 1. Microglial priming, activation, and IL-1 $\beta$ synthesis. Microglial activation status was examined at $2 \mathrm{~h}$ post-intrahippocampal IL-1 $\beta(10 \mathrm{ng})$ or TNF- $\alpha(300 \mathrm{ng})$ challenge in NBH and ME7 animals. Hippocampal CA1 IBA-1 microglial labeling $\times 20(\boldsymbol{a}-\boldsymbol{f})$ and $\times 100(\boldsymbol{g}-\boldsymbol{i})$. Hippocampal TNF- $\alpha$ labeling $\times 5(\boldsymbol{j}-\boldsymbol{o}) . \boldsymbol{n}$, Inset shows TNF- $\alpha$ labeling, post-intrahippocampal LPS, with and without pre-absorption of the antibody with excess TNF- $\alpha$. Hippocampal IL-1 $\beta$ labeling is shown at $\times 20(\boldsymbol{p}-\boldsymbol{u})$. $\boldsymbol{u}$, Inset shows IL-1 $\beta$-positive microglia adjacent to unlabeled astrocytic-like nucleus. Fluorescent double labeling of IBA-1 (594 nm) with IL-1 $\beta$ (488 nm) and Hoechst 33258 (blue) in ME7 animals $2 \mathrm{~h}$ post IL-1 $\beta$ (I-III) or TNF- $\alpha$ (IV-VI).

Nuclear localization of p65 was not readily apparent in NBH and ME7 animals. However, following both IL- $1 \beta$ and TNF- $\alpha$ challenges there was clear nuclear localization of p65 in both NBH and ME7 animals. These cells, positive for nuclear localized p65, were more frequent in ME7 animals challenged with IL-1 $\beta$ (Fig. $2 e$ ) or TNF- $\alpha$ (Fig. $2 f$ ) than in NBH animals challenged with IL-1 $\beta$ (Fig. $2 b$ ) or TNF- $\alpha$ (Fig. $2 c$ ) and included nuclei resembling those of both astrocytes (Fig. 2f, large and round, white arrow) and microglia (Fig. $2 f$, small and often somewhat elongated, black arrow).

We assessed glial immunolabeling for the chemokine CCL2 (macrophage chemoattractant protein, MCP-1) and found no readily detectable parenchymal CCL2 in NBH (Fig. $2 g$ ) and very few cells adjacent to the injection track in vehicle-injected ME7
(Fig. 2j) animals (but not sham operated). NBH animals challenged with TNF- $\alpha$ (Fig. $2 i$ ) showed barely discernible levels of parenchymal CCL2 induction, whereas ME7 animals challenged with TNF- $\alpha$ (Fig. 2l) showed a very robust induction of CCL2. ME7 animals challenged with IL- $1 \beta$ (Fig. $2 k$ ) also showed a very robust induction of CCL2, but once again there was little or no detectable parenchymal induction of CCL2 in NBH animals treated with IL-1 $\beta$ (Fig. $2 h$ ). Thus, ME7 animals show an exaggerated induction of CCL2 expression following both IL-1 $\beta$ and TNF- $\alpha$ challenges. The vast majority of the CCL 2 protein appears clustered in granules surrounding large round nuclei resembling those of astrocytes while small, elongated microglial-like cells remain negative (Fig. $2 l$, inset). 

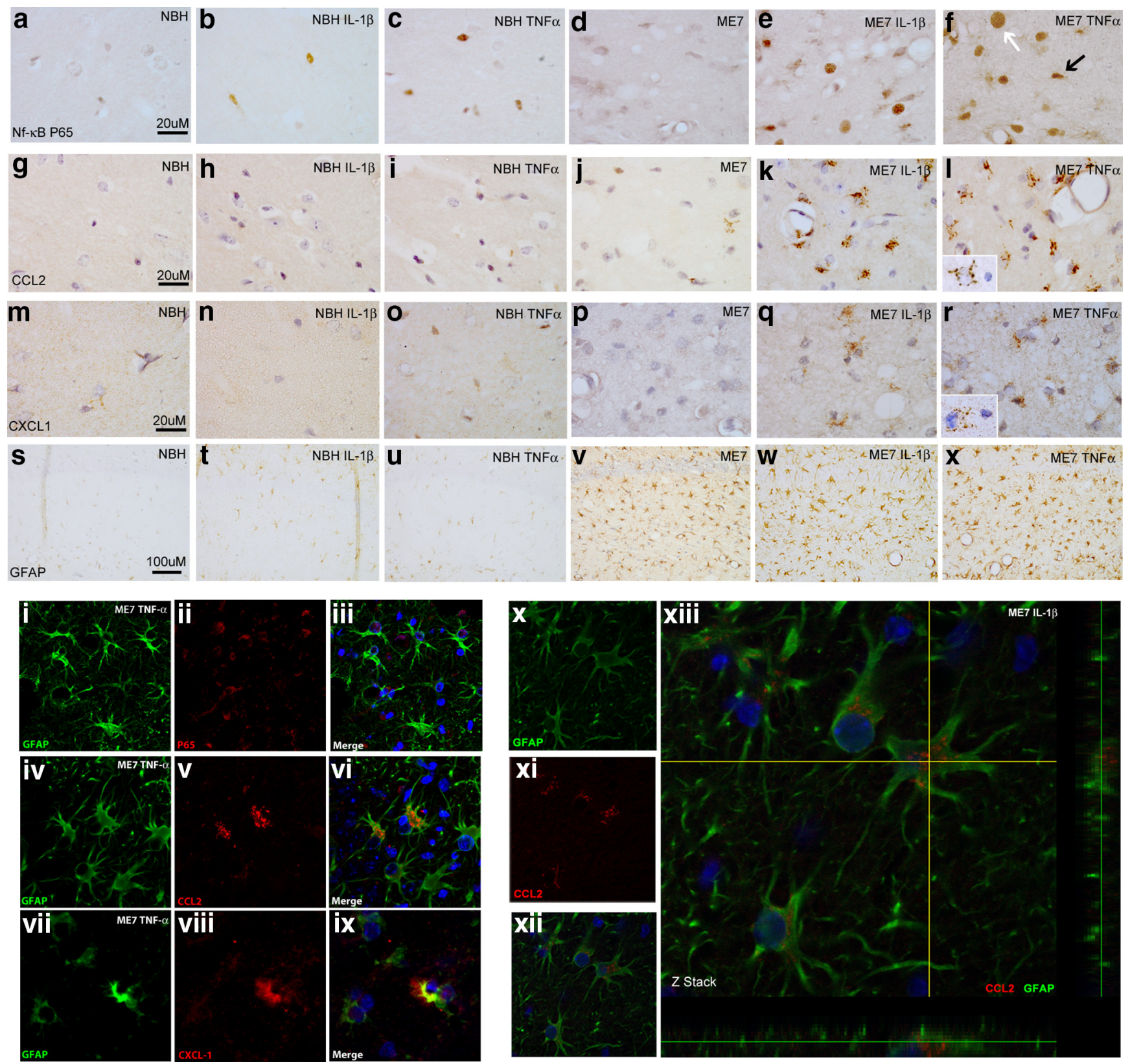

Figure 2. Astrocyte priming, activation, and chemokine synthesis. NF $\kappa$ B activation and chemokine expression $2 \mathrm{~h}$ post intrahippocampal IL-1 $\beta$ (10 ng) or TNF- $\alpha$ ( $300 \mathrm{ng})$ challenge of NBH and ME7 animals. NF $\kappa B$ p65 labeling $(\times 100)$ in the hippocampus $(\boldsymbol{a}-\boldsymbol{f})$ with astrocytic-like nucleus indicated by white arrow and microglial-like nucleus indicated by black arrow in $\boldsymbol{f}$. Hippocampal CCL2 labeling at $\times 100$ magnification $(\boldsymbol{g}-\boldsymbol{I})$. CXCL1 labeling at $\times 100$ magnification $(\boldsymbol{m}-\boldsymbol{r}) . \boldsymbol{I}, \boldsymbol{r}$, Insets show CCL2 and CXCL1 labeling, respectively, associated with astrocyte-like nucleus adjacent to microglia-like nucleus devoid of labeling. Hippocampal CA1 GFAP astrocyte labeling in NBH and ME7 animals is shown at $\times 20$ (s-x). Fluorescent labeling of GFAP (488 nm), p65 (633 nm), CCL2 (594 $\mathrm{nm})$, and CXCL1 (594 nm) $2 \mathrm{~h}$ post TNF- $\alpha(i-i x)$ or IL-1 $\beta$ challenge $(x-x i i i)$.

We also performed immunolabeling for the neutrophil chemoattractant CXCL1 (CINC-1, KC, and GRO $\alpha$ ). There was no detectable parenchymal CXCL1 induction in either NBH (Fig. $2 m$ ) or ME7 (Fig. $2 p$ ) animals. NBH + IL-1 $\beta$ (Fig. $2 n$ ) animals showed a low-level induction of CXCL1 barely discernible even at $100 \times$ magnification. However, ME7 + IL-1 $\beta$ (Fig. $2 q$ ) animals showed a robust and clearly demonstrable CXCL1 induction. ME7 + TNF- $\alpha$ (Fig. $2 r$ ) showed a large induction of CXCL1 similar to ME7 + IL-1 $\beta$ (Fig. $2 q$ ). NBH animals showed no induction of CXCL1 following TNF- $\alpha$ challenge (Fig. 2o). Once again, CXCL1 appeared clustered around astrocytic-like nuclei but not microglial-like nuclei (Fig. $2 r$, inset). Thus, ME7 animals show exaggerated induction of CXCL1 and CCL2 following both
IL- $1 \beta$ and TNF- $\alpha$. This is not because there are more astrocytes: not a single cell in any of the NBH animals shows an equivalent response to what is observed in a large number of the astrocytes in the ME7 brain.

Although we have previously described exaggerated responses of primed microglia to acute LPS challenge (Cunningham et al., 2005) and here show that this is also true for exaggerated IL- $1 \beta$ responses to acute IL- $1 \beta$ challenge or TNF- $\alpha$ challenge, the labeling patterns with NF $\kappa \mathrm{B}$ p65, CCL2, and CXCL1 were all suggestive of a predominantly astrocytic localization. That is, the labeling manifested as a "cloud" of vesicles proximal to large rounded nuclei resembling astrocytes rather than small elongated nuclei resembling microglia. This was a consistent 
feature and it was difficult to identify any chemokine labeling reliably associated with microglial-like nuclei. Astrogliosis is known to occur in ME7. This is evident in the GFAP-labeled sections of ME7 animals (Fig. 2v), compared with NBH (Fig. 2s). The ME7-associated astrogliosis is prominent in the stratum radiatum of the hippocampus, which is the region of the most intense chemokine production in the current study. Thus both morphology and location suggested that the astrocytes were the source of chemokines.

To confirm our observations from light microscopy, we double labeled p65, CCL2, and CXCL1 with GFAP. Figure 2, $i-i x$, shows double labeling of these markers in an ME7 animal following TNF- $\alpha$ challenge. It is clear that p65 (red) labeling is within the nucleus of the GFAP (green)-positive astrocytic cells (Fig. 2iii). There is some limited evidence of microglial p65 nuclear localization in smaller more elongated nuclei, but this is not as robust by confocal imaging as was the case by light microscopy. This may be due to generally weaker p65 labeling by confocal imaging. Figure $2 v i$ shows the presence of CCL2-positive (red) vesicles inside a GFAP-positive astrocyte (green), while Figure 2ix shows the presence of CXCL1 (red) in the cell body of an astrocyte. There was very limited chemokine labeling not associated with astrocytes or the vasculature arguing against a significant contribution from microglia. These images indicate that ME7 animals challenged with TNF- $\alpha$ show activation of astrocytes resulting in production of the chemokines CCL2 and CXCL1. This astrocyte localization of the cytokine-induced chemokine was also true of IL- $1 \beta$-challenged animals: CCL2 (red) colocalized with astrocytic GFAP (green) following IL- $1 \beta$ challenge in ME7 animals (Fig. 2xiii). Collectively the data from Figure 2 indicate that astrocytes in the degenerating brain are primed by the primary pathology to show exaggerated chemokine responses to subsequent stimulation with cytokines. Under these neurodegenerative conditions, acutely administered IL- $1 \beta$ robustly induces CCL 2 and TNF- $\alpha$ robustly induced CXCL1 as soon as $2 \mathrm{~h}$ post challenge with these cytokines.

\section{Analysis of microglial and astrocytic transcripts $2 \mathrm{~h}$ post cytokine challenge}

Given our observation of both microglial and astrocyte priming in the diseased brain, and exaggeration of cytokine and chemokine responses post-IL- $1 \beta$ or TNF- $\alpha$, it was important to interrogate whether there was exaggerated or differential transcription of these genes and others that might confirm the further activation of astrocytes. We examined hippocampal mRNA transcripts of cytokines, chemokines, and markers of astrocytic activation at $2 \mathrm{~h}$ post intrahippocampal TNF- $\alpha$ or IL- $1 \beta$.

Consistent with the robust expression of IL- $1 \beta$ observed by immunolabeling at $2 \mathrm{~h}$, both IL- $1 \beta$ and TNF- $\alpha$ treatment lead to significant transcription of IL- $1 \beta$ (Fig. $3 a$; main effect of treatment $\left.p<0.001, F_{(2,18)}=13.05\right)$. There were also main effects of disease and an interaction between disease and treatment $(p<$ $\left.0.05, F_{(2,18)}=3.65\right)$, and levels were significantly increased in ME7 animals compared with NBH animals following both TNF- $\alpha$ (Bonferroni post hoc, $p<0.01)$ and IL-1 $\beta(p<0.001)$ challenge.

Although de novo TNF- $\alpha$ protein was not visible by immunolabeling, there was a main effect of treatment on TNF- $\alpha$ mRNA levels (Fig. $3 b ; p<0.05, F_{(2,21)}=3.53$ ) but IL-1 $\beta$ was the more robust driver of TNF- $\alpha$ transcription: ME7 + IL- $1 \beta$ animals were significantly different from NBH + IL- $1 \beta$ animals (Bonferroni, $p<0.01$ ), while TNF- $\alpha$ induced TNF- $\beta$ transcription equally in both NBH and ME7 animals.
CCL2 (Fig. 3c) was robustly induced by cytokine treatment $\left(p<0.001, F_{(2,21)}=10.46\right)$, but also showed a main effect of disease $\left(p<0.001, F_{(1,21)}=24.23\right)$. Importantly, there was an interaction between these two effects $\left(p<0.05, F_{(2,21)}=4.303\right)$, and CCL 2 mRNA was significantly higher in ME7 + TNF- $\alpha$ and ME7 + IL- $1 \beta$ compared with NBH groups similarly challenged (Bonferroni post hoc tests, $p<0.01$ ).

CXCL1 analysis, in particular, showed a robust phenotypic switch between ME7 + saline and ME7 + IL- $1 \beta$ or TNF- $\alpha$ (Fig. $3 d$ ). There was no expression in saline-treated animals (NBH or ME7) and no effect of disease but a main effect of treatment $\left(p<0.001, F_{(2,17)}=22.93\right)$. CXCL1 transcription was induced by TNF- $\alpha$ and IL- $1 \beta$ approximately equally in both NBH and ME7 animals. This suggests that the higher levels of CXCL1 protein observed in the ME7 astrocyte population are regulated translationally.

RANTES (Fig. 3e) is a T-cell chemoattractant chemokine, and is significantly elevated by disease $\left(p<0.001, F_{(1,18)}=58.03\right)$ but is also increased by TNF- $\alpha$, showing a significant effect of treatment $\left(p<0.05, F_{(2,18)}=5.904\right)$ and an interaction between treatment and disease $\left(p<0.05, F_{(2,18)}=4.463\right)$, with no obvious effect of TNF- $\alpha$ in NBH animals. IL- $1 \beta$ appeared to have no effect on RANTES expression.

CXCL10 is a chemokine responsible for attracting monocytes and T-cells and was significantly induced by both IL- $1 \beta$ and TNF- $\alpha$ (Fig. $3 f)$. There was a main effect of treatment $(p<0.001$, $\left.F_{(2,22)}=10.95\right)$, of disease $\left(p<0.001, F_{(1,22)}=48.26\right)$, and an interaction between these factors $\left(p<0.01, F_{(2,22)}=7.276\right)$, which indicates much more robust acute induction in ME7 animals than in NBH. Bonferroni post hoc tests indicate that CXCL10 (Fig. $3 f$ ) is significantly elevated following both TNF- $\alpha$ and IL-1 $\beta$ treatment in ME7 versus NBH animals $(p<0.001)$.

Astrogliosis is a significant feature of the ME7 strain of murine prion disease and GFAP mRNA (Fig. $3 g$ ) was significantly elevated in all ME7 animals (main effect of disease: $p<0.001$, $\left.F_{(1,18)}=147.2\right)$ but was not altered $2 \mathrm{~h}$ after intrahippocampal cytokine treatment.

PTX3 is a transcriptionally upregulated marker of reactive astrocytosis (Zamanian et al., 2012; Fig. $3 h$ ) and is significantly increased by disease $\left(p<0.001, F_{(1,18)}=52.72\right)$. However, it was very robustly induced by cytokine treatment $\left(p<0.01, F_{(2,18)}=\right.$ $9.521)$ and there was a significant interaction between disease and treatment $\left(p<0.01, F_{(2,18)}=8.245\right)$, demonstrating that PTX3 is robustly increased by TNF- $\alpha$ and IL- $1 \beta$ in ME7, but this is barely discernible in NBH animals similarly challenged (Bonferroni post $h o c, p<0.001)$. This strongly supports an exaggerated astrocyte response to cytokine stimulation.

STEAP4 (Fig. 3i) is also a transcriptionally regulated marker of astrocytic activation (Zamanian et al., 2012) and was significantly elevated by disease $\left(p<0.01, F_{(1,18)}=12.36\right)$. Treatment also had a significant effect on expression $\left(p<0.001, F_{(2,18)}=\right.$ $13.05)$ and, while TNF- $\alpha$ had more robust effects on STEAP4 in ME7 than in NBH animals (Bonferroni post hoc, $p<0.001$ ), IL- $1 \beta$ treatment had equivalent effects on STEAP4 in both NBH and ME7. There was an interaction between disease and treatment $\left(p<0.05, F_{(2,18)}=5.516\right)$ indicating more robust effects of TNF- $\alpha$ in ME7 animals with respect to NBH.

Generally these data show more robust effects of cytokine treatment on cytokine, chemokine, and astrocyte transcripts in ME7 than in NBH animals. While many markers are already elevated somewhat in ME7, others such as CXCL1 are not. CXCL1 was induced to equivalent levels in NBH and ME7 animals challenged with TNF- $\alpha$ and IL- $1 \beta$ but was very robustly synthesized at the pro- 


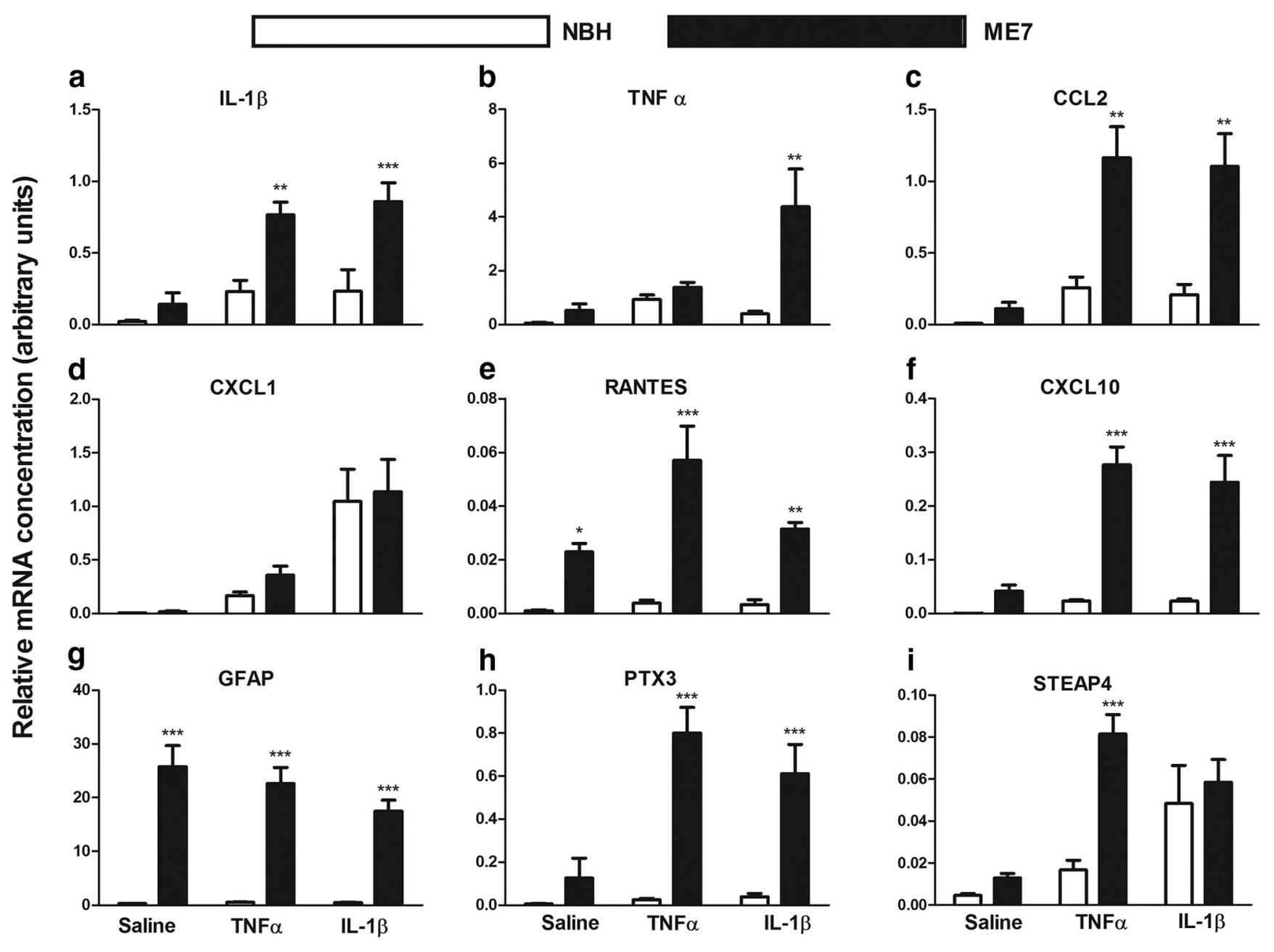

Figure 3. Analysis of cytokine, chemokine, and astrocytosis transcripts. Hippocampal expression of transcripts for inflammatory genes was analyzed $2 \mathrm{~h}$ post intrahippocampal IL-1 $\beta$ (10 ng) or TNF- $\alpha$ (300 ng). $\boldsymbol{a}$, IL-1 $\beta ; \boldsymbol{b}$, TNF- $\alpha ; \boldsymbol{c}$, CCL2; $\boldsymbol{d}$, CXCL1; $\boldsymbol{e}$, RANTES; $\boldsymbol{f}$, CXCL10; $\boldsymbol{g}$, GFAP; $\boldsymbol{h}$, PTX3; $\boldsymbol{i}$, STEAP4. Data were analyzed using two-way ANOVA and main effects and interactions are described in the main text. Statistically significant differences between NBH and ME7 by Bonferroni post hoc tests are denoted by ${ }^{* *} p<0.001,{ }^{* *} p<0.01$, and ${ }^{*} p<0.05$. All data are represented as the mean \pm SEM and $n=4$ for all groups except for the analysis of TNF- $\alpha$, CCL2, and CXCL10, in which both ME7 + saline and ME7 + IL- $1 \beta$ had $n=6$.

tein level by ME7 astrocytes, indicating the exaggeration of astroglial responses may also occur at the level of regulation of translation.

PTX3 and STEAP4 both indicate exaggerated astrocytic activation in ME7 animals following intrahippocampal challenges. Defining priming as the propensity of a cell to react in an exaggerated manner to a secondary stimulus, we have demonstrated exaggerated induction of astrocytic transcripts and chemokine proteins in astrocytes in the degenerating brain with respect to expression in the normal brain following central sterile inflammatory insult.

\section{Neutrophil infiltration at $24 \mathrm{~h}$}

The exaggerated levels of the neutrophil chemoattractant protein CXCL1 induced in response to TNF- $\alpha$ and IL- $1 \beta$ in the ME7 brain (Fig. 2) predicted significant effects on cellular infiltration. We therefore assessed neutrophil infiltration at $24 \mathrm{~h}$ post cytokine challenge using MBS-1, a polyclonal anti-neutrophil antiserum. Neutrophils were not found in the parenchyma of $\mathrm{NBH}+$ saline (Fig. $4 a$ ) or ME7 + saline animals (Fig. $4 d$ ). There was some neutrophil infiltration following both IL- $1 \beta$ and TNF- $\alpha$ in the $\mathrm{NBH}$ animals, although this was limited to the injection site with TNF- $\alpha$ (Fig. $4 b, c$, respectively). ME7 + IL-1 $\beta$ animals (Fig. $4 e$ ) showed exaggerated neutrophil infiltration throughout the hip- pocampus compared with $\mathrm{NBH}+\mathrm{IL}-1 \beta$-treated animals (Fig. $4 b)$. Quantification $\left({ }^{4} g\right)$ and two-way ANOVA show that there was a main effect of IL- $1 \beta\left(p<0.001, F_{(1,11)}=67.94\right)$, a main effect of disease $\left(p<0.01, F_{(1,11)}=12.15\right)$, and an interaction between treatment and disease $\left(p<0.01, F_{(1,11)}=12.13\right)$. Similarly ME7 + TNF- $\alpha$ animals (Fig. $4 f$ ) showed an exaggerated infiltration compared with NBH + TNF- $\alpha$ (Fig. $4 c)$. Infiltration occurred throughout the parenchyma of the injected hemisphere in ME7 animals rather than limited to the injection site, as was the case in NBH animals. Following TNF- $\alpha$ challenge (Fig. $4 h$ ), there was a main effect of treatment $\left(p<0.001, F_{(1,10)}=29.15\right)$ and an interaction between disease and treatment $\left(p<0.05, F_{(1,10)}=\right.$ $6.67)$. These data demonstrate that infiltration of neutrophils is exaggerated in the ME7 brain challenged with either IL- $1 \beta$ or TNF- $\alpha$ compared with NBH animals similarly challenged.

Neutrophil infiltration is also influenced by events at the cerebral endothelium. Figure 5, $a-d$, shows representative images of CCL2 and CXCL1 expression in the ME7 animals challenged with IL- $1 \beta$ and TNF- $\alpha$-challenged animals at the major blood vessels of the hippocampus and at the glia limitans, which separates the hippocampus from the CSF. Unlike astrocytic labeling, vascular labeling with CXCL1 and CCL2 was always detectable in both NBH and ME7 animals. Figure $5 e$ shows the colocalization 

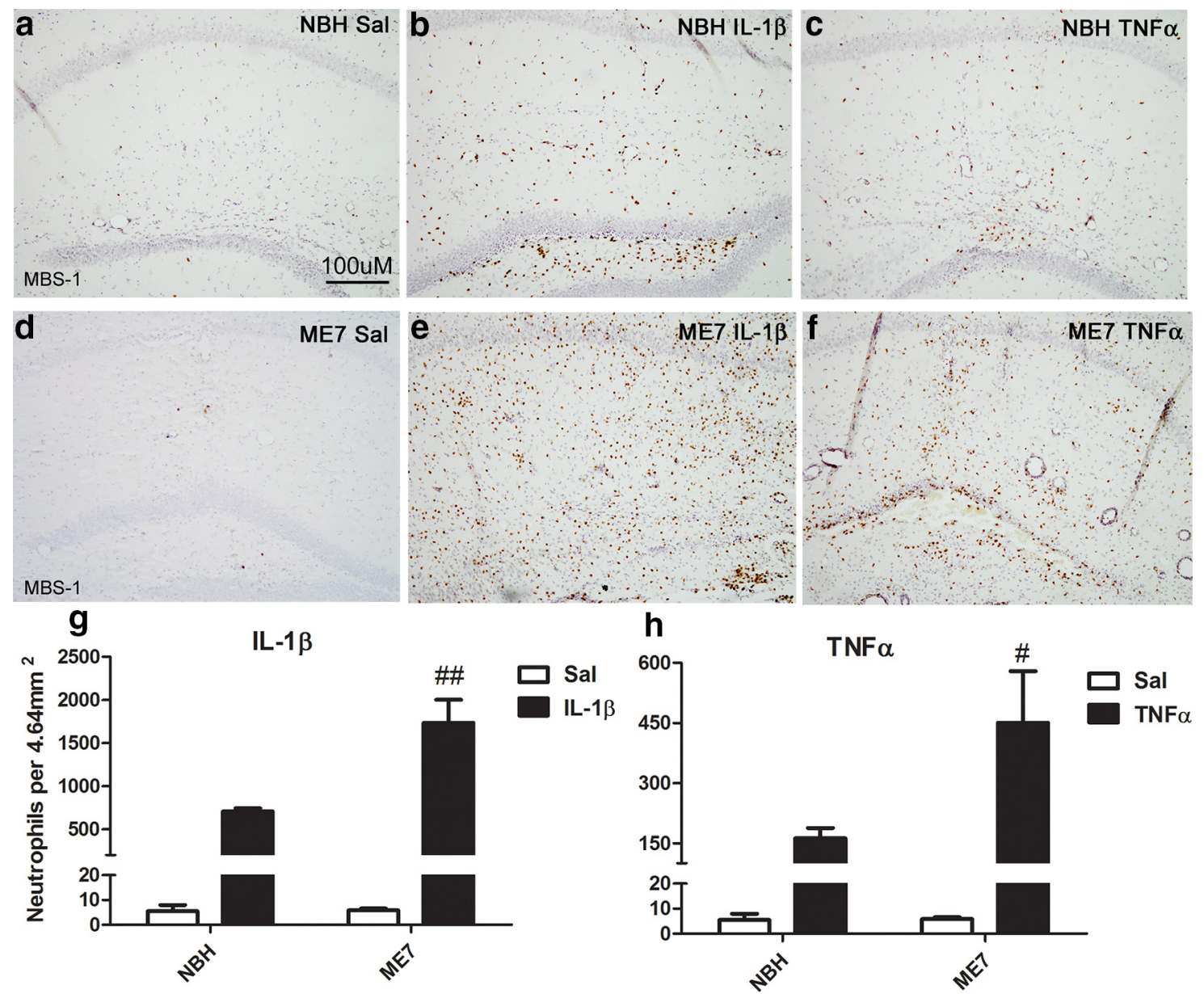

Figure 4. Cytokine-induced neutrophil infiltration. Hippocampal neutrophil infiltration at $24 \mathrm{~h}$ post intrahippocampal IL-1 $\beta$ (10 ng) or TNF- $\alpha$ ( $300 \mathrm{ng})$ challenge. MBS-1 neutrophil labeling at $\times 20$ magnification $(\boldsymbol{a}-\boldsymbol{f})$ at $24 \mathrm{~h}$ post challenge. Quantification of neutrophils in an area of $4.64 \mathrm{~mm}^{2}$ centered on the injected dorsal hippocampus following IL-1 $\beta(\boldsymbol{g})$ and TNF- $\alpha(\boldsymbol{h})$ injection. Data were analyzed using a two-way ANOVA followed by Bonferroni post hoc test. Interactions between treatment and disease are denoted by $\# p<0.05$ and ${ }^{\# \#} p<0.01$. All data are represented as the mean \pm SEM, $n=3-5$ for all groups.

of the astrocytic marker GFAP with CCL2 proximal to a blood vessel and CCL2 on the luminal surface of the vessel, where it can stimulate circulating macrophages. At $24 \mathrm{~h}$ post challenge there is a differential recruitment of cells to these surfaces by IL- $1 \beta$ and TNF- $\alpha$. The neutrophil marker MBS-1 shows a large number of neutrophils in the parenchyma of the ME7 + IL- $1 \beta$ group but few, if any, cells, remaining at the glia limitans (Figure 5j). However, in the NBH + IL-1 $\beta$ group, there remains a significant build-up of neutrophils at the glia limitans (Figure $5 \mathrm{~g}$ ), suggesting more successful extravasation of neutrophils in ME7 animals with respect to NBH animals. Thus neutrophils were recruited in both NBH and ME7 but extravasated more readily in those animals with robust CXCL1 expression in the brain parenchyma (Fig. 4).

In the ME7 + TNF- $\alpha$ (Figure $5 k$ ) group there is a large recruitment of cells to the ventricular space between hippocampus and thalamus, which is greatly exaggerated compared with the NBH + TNF- $\alpha$ group (Figure $5 h$ ); however, only a small number of these are MBS-1 positive. Most are positive for the macrophage marker CD68. Although this cannot distinguish between peripheral macrophages and microglia, here in the ventricular space, its presence in abundance indicates that the majority of cells recruited to the glia limitans in the ME7 + TNF- $\alpha$ group are monocytes (Figure $5 q$ ). There is some recruitment of CD68-positive cells following IL- $1 \beta$ challenge; however, the recruitment is much larger in the
TNF- $\alpha$ groups, indicating that there remains a different profile of recruitment between ME7 + TNF- $\alpha$ and ME7 + IL-1 $\beta$. Even though TNF- $\alpha$ does induce robust neutrophil infiltration, it still appears to recruit monocytic cells more effectively than does IL- $1 \beta$.

\section{Infiltration at $72 \mathrm{~h}$}

Having demonstrated robust neutrophil infiltration at $24 \mathrm{~h}$ and observed significant CD68-positive monocytes at the glia limitans in TNF-treated animals (both NBH and ME7), we examined TNF-treated animals at $72 \mathrm{~h}$ to assess whether NBH and ME7 showed differential cellular infiltration. Based on our previous observations, we investigated the hypothesis that exaggerated astrocytic CCL2 production at $2 \mathrm{~h}$ in ME7 animals would exert a differential impact on macrophage infiltration in ME7 versus $\mathrm{NBH}$ animals.

It is immediately apparent from assessing hematoxylin counterstain that ME7 animals are hypercellular in the hippocampus compared with $\mathrm{NBH}$ (Fig. 6, compare $c, a$ ) due to diseaseassociated astrocytosis and microgliosis, and that TNF- $\alpha$ exaggerated this hypercellularity in ME7 animals (Fig. 6, compare $d, c$ ) and the increase was greater in ME7 animals compared with that in NBH animals (Fig. 6b). Multiple perivascular cuffs were observed in each field examined in ME7 + TNF- $\alpha$ animals, indicative of cellular infiltration from the periphery. To assess the 

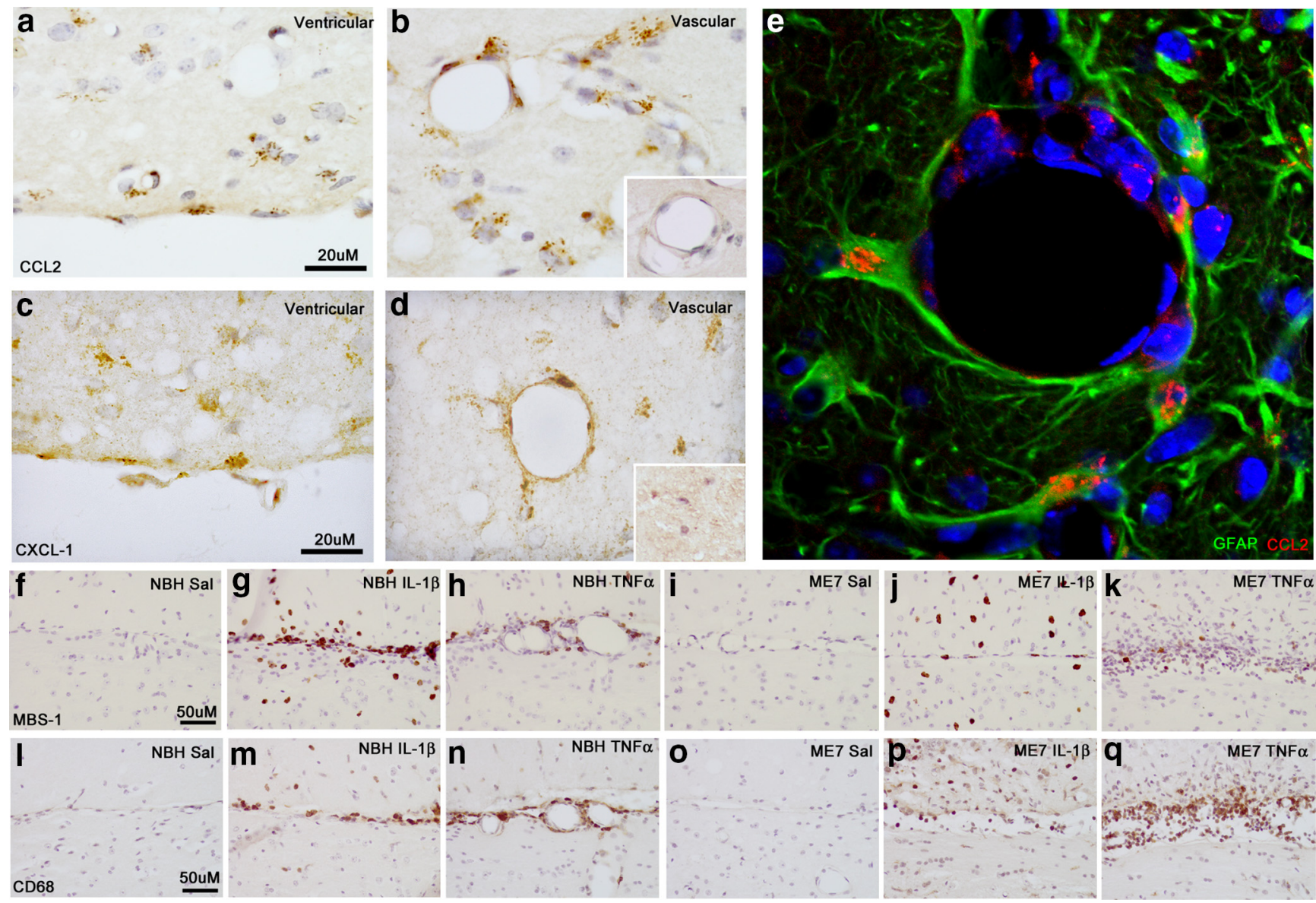

Figure 5. Chemokine expression and immune cell recruitment at brain barriers. Chemokine expression at ventricular and vascular surfaces at $2 \mathrm{~h}$ post intrahippocampal cytokine challenge. Representative images of $\mathrm{CCL} 2$ at the ventricular $(\boldsymbol{a})$ and vascular $(\boldsymbol{b})$ surfaces of ME7 animals $\times 100$ at $2 \mathrm{~h}$. $\boldsymbol{b}$, Inset shows CCL2 labeling with and without pre-absorption of the antibody with excess CCL2. CXCL-1 at the ventricular (c) and vascular (d) surfaces $\times 100$ at $2 \mathrm{~h}$. $\boldsymbol{d}$, Inset shows XXL1 labeling with and without pre-absorption of the antibody with excess CXCL1. GFAP and CCL2 colocalization at a hippocampal blood vessel at $2 \mathrm{~h}$ post TNF- $\alpha(\boldsymbol{e})$. MBS-1 neutrophil labeling at the ventricular membrane at $24 \mathrm{~h}$ post challenge with IL-1 $\beta$ (10 ng) or TNF- $\alpha(300 \mathrm{ng})$ challenge $(\times 40, \boldsymbol{f}-\boldsymbol{k})$. CD68 macrophage labeling $(\times 40, \boldsymbol{I}-\boldsymbol{q})$ at the ventricular surface (glia limitans) at $24 \mathrm{~h}$ post challenge with IL-1 $\beta(10 \mathrm{ng})$ or TNF- $\alpha(300 \mathrm{ng})$.

contribution of neutrophils to the increased cell numbers seen at $72 \mathrm{~h}$ we examined MBS-1-positive cells in the hippocampus of these animals. Occasional neutrophils could be seen in NBH + TNF- $\alpha$ (Fig. $6 b$ ) and ME7 + TNF- $\alpha$ (Fig. $6 d$ ) animals; however, there were few neutrophils remaining in the hippocampus of these groups at $72 \mathrm{~h}$ (Fig. $6 \mathrm{~m}$ ) compared with their peak at $24 \mathrm{~h}$. There was no significant effect of treatment or disease by two-way ANOVA. Thus, neutrophils account for an insignificant proportion of the increased cellularity at $72 \mathrm{~h}$.

T-cell infiltration was also examined. Consistent with prior studies, there were some CD3-positive cells in the hippocampus of ME7 animals (Fig. 6c); however, these were somewhat variable in number. CD3 labeling (Fig. 6e-h) revealed TNF- $\alpha$-induced T-cell infiltration and this was heightened in ME7 + TNF- $\alpha$ (Fig. $6 h$ ) animals compared with NBH + TNF- $\alpha$ (Fig. $6 f$ ). Quantification (Fig. 6n) showed a main effect of both treatment $(p<0.01$, $\left.F_{(1,18)}=11.20\right)$ and disease $\left(p<0.001, F_{(1,18)}=27.38\right)$ with an interaction between these two factors $\left(p<0.05, F_{(1,18)}=4.757\right)$. Thus T-cells are more readily recruited to the ME7 brain than to the normal brain, but they still make a relatively minor contribution to hypercellularity observed after TNF- $\alpha$ challenge.

We used the readily quantifiable myeloid lineage marker Pu.1 to label both macrophage and microglial nuclei to assess macrophage/microglial contribution to the observed hypercellularity. This marker shows both the ME7 disease-associated microgliosis
(Fig. 6, compare $k, i$ ) and TNF- $\alpha$-induced focal increases in macrophages. Quantification was performed in an area close to the injection track to avoid "diluting" the infiltrating cells among the considerable resident Pu.1-positive microglial population of the ME7 brain (Fig. 6o) and two-way ANOVA showed significant effects of disease $\left(p<0.001, F_{(1,24)}=24.53\right)$ and treatment $(p<$ $\left.0.01, F_{(2,24)}=6.100\right)$. Bonferroni post hoc shows that Pu.1-labeled cells are significantly greater in number in ME7 + TNF- $\alpha$ versus $\mathrm{NBH}+\mathrm{TNF}-\alpha(p<0.001)$. To interrogate whether these Pu.1positive cells originate outside the brain we used the Mc21 CCR2 antibody, which depletes systemic monocytes (Bruhl et al., 2007; Yona et al., 2013). Administration of Mc21 before intrahippocampal TNF- $\alpha$ administration significantly decreased Pu.1positive macrophages in the hippocampus (effect of treatment $p<0.05, F_{(1,18)}=6.313$; Bonferroni post hoc comparison of ME7 + TNF- $\alpha$ versus ME7 + TNF- $\alpha+$ Mc21: $p<0.05)$. This indicates that infiltrating monocytes are contributing significantly to the increased cell numbers seen at $72 \mathrm{~h}$ post TNF- $\alpha$ administration. The number of monocytes infiltrating the brain, rather than the fold increase from baseline (ME7+saline), is the most relevant parameter and this number is considerably higher in ME7 + TNF- $\alpha$ than in NBH + TNF- $\alpha$ (Fig. 6o).

Although we also observed increased numbers of Ki67-positive cells, indicating increased cellular proliferation in the TNF- $\alpha$ injected hippocampus, we failed to find significant double label- 


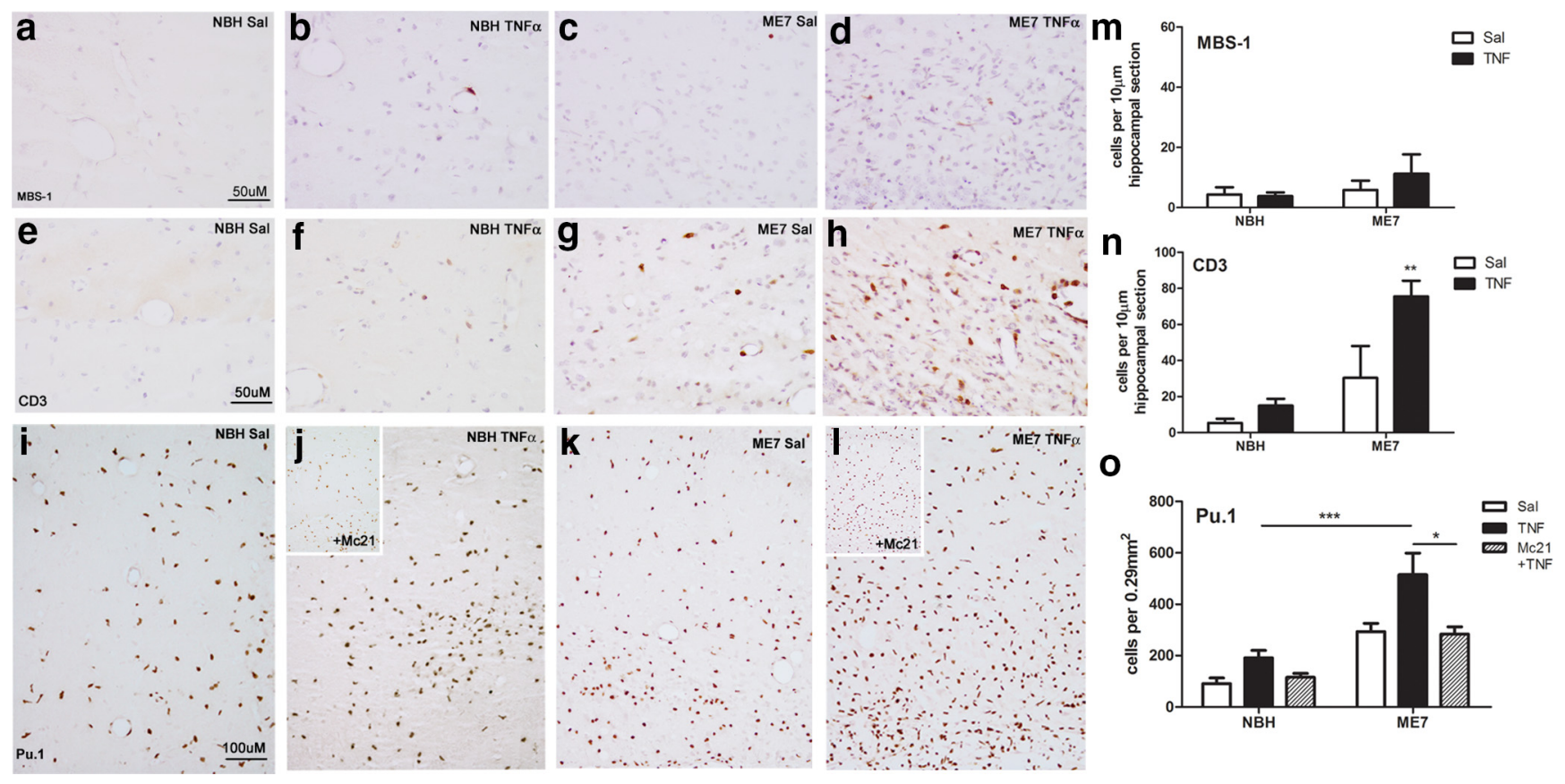

Figure 6. Immune cell infiltration at $72 \mathrm{~h}$. Cellular infiltration at $72 \mathrm{~h}$ post intrahippocampal TNF- $\alpha(300 \mathrm{ng})$ challenge. Hippocampal MBS-1 neutrophil labeling $\times 40$ (a- $\boldsymbol{d}$ ), CD3 T-cell labeling $\times 40(\boldsymbol{e}-\boldsymbol{h})$, and Pu.1 macrophage/microglial labeling $\times 20(\boldsymbol{i}-\boldsymbol{I})$. Quantification of MBS-1-positive neutrophils $(\boldsymbol{m})$ and CD3-positive T-cells $(\boldsymbol{n})$ in the injected hippocampus at 72 h. Pu.1-positive macrophages and microglia were quantified per $0.29 \mathrm{~mm}^{2}$ of the injected hippocampus $(\boldsymbol{o})$. The latter were quantified in the presence and absence of peripherally administered Mc21 to deplete circulating monocytes. Data were analyzed using two-way ANOVA (full analysis in main text) followed by Bonferroni post hoc test. Selected statistically significant pairwise comparisons are denoted by ${ }^{*} p<0.05,{ }^{* *} p<0.01,{ }^{* * *} p<0.001$. All data are represented as the mean $\pm \mathrm{SEM}, n=3-7$.

ing with Pu.1 (data not shown). Collectively these data suggest that significant monocyte infiltration is the major contributor to the increased hypercellularity in ME7 + TNF- $\alpha$ animals at $72 \mathrm{~h}$ post challenge.

\section{Discussion}

Microglia in the degenerating brain show exaggerated IL- $1 \beta$ production in response to acute sterile inflammation induced by IL- $1 \beta$ or TNF- $\alpha$. We also show that astrocytes are similarly primed to produce exaggerated chemokine responses to acute cytokine challenge. This markedly heightened chemokine response induces exaggerated neutrophil, T-cell, and macrophage infiltration in the diseased brain.

\section{Primed microglia}

Microglia in ME7 animals switch their phenotype upon central challenge with LPS, robustly producing iNOS and IL-1 $\beta$ (Cunningham et al., 2005; Hughes et al., 2010). Here, both IL- $1 \beta$ and TNF- $\alpha$ induce robust IL- $1 \beta$, cell soma condensation, and process retraction, likely reflecting a more phagocytic phenotype (Hughes et al., 2010). Both IL- $1 \beta$ and TNF- $\alpha$ can trigger this phenotypic change and this occurs as soon as $2 \mathrm{~h}$ post cytokine. Moreover, since both cytokines robustly induced these changes only in ME7 animals (at $2 \mathrm{~h}$ ), one can say that microglia in the ME7 animals are primed to produce exaggerated responses to the inflammatory cytokines IL- $1 \beta$ and TNF- $\alpha$. This expands the repertoire of inflammatory molecules to which primed microglia are demonstrated to respond in an exaggerated fashion and is significant since molecules such as LPS are rarely experienced in the brain parenchyma.

\section{Astrocyte priming and chemokine production}

Administration of IL- $1 \beta$ and TNF- $\alpha$ also induced exaggerated astrocyte synthesis of both CXCL1 and CCL2 in the ME7 brain with respect to $\mathrm{NBH}$ animals similarly challenged. This indicates a priming of the astrocyte population that may be analogous to microglial priming (Cunningham et al., 2005) suggesting generally heightened sensitivity of the degenerating CNS to subsequent inflammatory stimulation. This necessitates a clear definition of the priming concept. We use the term priming to convey the propensity of a particular cell type to make an exaggerated response to a typical stimulus. Therefore, priming has a general use but not a specific molecular or cellular identity. In the case of primed microglia, they show an exaggerated IL- $1 \beta$ response to LPS (Cunningham et al., 2005; Godbout et al., 2005) and to IL-1 $\beta$ and TNF- $\alpha$ (in the current study). Conversely, primed astrocytes show exaggerated CCL2 and CXCL1 responses to IL- $1 \beta$ or TNF- $\alpha$ challenge. Astrocyte priming has long been suggested from in vitro studies: IFN- $\gamma$-sensitized astrocytes to exaggerated responses to subsequent LPS or IL- $1 \beta$ (Chung and Benveniste, 1990). More recently, astrocytes were primed by IL- $1 \beta$, TNF- $\alpha$, or LPS-stimulated microglial conditioned media to produce exaggerated chemokine and CAM synthesis upon TLR2 stimulation (Henn et al., 2011). We have now demonstrated astrocyte priming in vivo, independent of exogenous TLR ligands, which would rarely appear in the brain. Microglial priming proved to be generic across multiple animal models of brain pathology and we predict that astrocyte priming will behave similarly.

Astrocyte priming may reduce selectivity of chemokine responses. It is reported that IL- $1 \beta$ induces CXCL1 and neutrophil infiltration (Campbell et al., 2002) and TNF- $\alpha$ induces CCL2 and monocyte infiltration (Campbell et al., 2005) and that these pathways do not significantly cross over (Schnell et al., 1999; Blond et al., 2002). Despite this there is in vitro evidence for TNF- $\alpha$ induction of CXCL1 (Wang et al., 2007; Lee et al., 2012; Zhang et al., 2013) and IL- $1 \beta$ induction of CCL2 (Jing et al., 2010; An et al., 2011; Fouillet et al., 2012). Intrathecal TNF- $\alpha$ induced spinal 
cord CXCL1 (Zhang et al., 2013) but demonstrations of this in the brain are lacking. Here both IL- $1 \beta$ and TNF- $\alpha$ robustly induced both CXCL1 and CCL2 in astrocytes of the degenerating brain. We cannot say whether the failure to observe this in normal animals reflects chemokine class-restricted expression or simply much lower chemokine expression. While exaggerated induction of microglial IL- $1 \beta$ by TNF- $\alpha$ could potentially explain the robust TNF- $\alpha$-induced CXCL1 observed here, we think this unlikely since it would require transcription, translation, maturation, secretion, and action of IL-1, followed by transcription and translation of CXCL1, all to be achieved in $2 \mathrm{~h}$ (although increased microglial IL- $1 \beta$ will likely contribute to events that occur after $2 \mathrm{~h}$ ). One might argue that the degree to which IL-1/ CXCL1 and TNF/CCL2 are discrete pathways has been overstated and that given a sufficient dose both cytokines can induce both chemokines. Regardless, our data suggest that chemokine induction and cellular infiltration are tightly regulated in the healthy brain but these restraints are loosened in the diseased brain, leading to more robust chemokine synthesis in response to both IL- $1 \beta$ and TNF- $\alpha$ stimulation. The mechanisms are currently unclear. IL-1RI and TNF-R p55 expression are elevated in the ME7-diseased brain (Murray et al., 2012), likely increasing sensitivity to these immune activators. Similarly, astrocytic NF $\kappa \mathrm{B}$ inhibition decreases chemokine expression (Brambilla et al., 2014) and it is plausible that increased astrocytic expression of $\mathrm{NF} \kappa \mathrm{B}$ subunits, and consequent increased transcriptional activation, may underpin exaggerated astrocyte responses to acute stimulation. That astrocytic $\mathrm{NF} \kappa \mathrm{B}$ activation is a key event in these exaggerated responses could be tested using selective inactivation of astroglial $\mathrm{NF} \kappa \mathrm{B}$ via expression of dominant-negative $\mathrm{I} \kappa \mathrm{B} \alpha$ under astrocyte-specific promoter control (Brambilla et al., 2005). Nonetheless, we also show evidence of post-transcriptional control in the current study: despite similar transcription of CXCL1 mRNA in IL-1-challenged ME7 and NBH animals, ME7 astrocytes translated CXCL1 to a much greater extent than those of NBH animals.

\section{Consequences of chemokine induction}

Intrahippocampal LPS recruits a mixed brain infiltrate, via induction of both IL- $1 \beta$ and TNF- $\alpha$, but intraparenchymal IL- $1 \beta$ and TNF- $\alpha$, given separately, are reported to more effectively recruit neutrophils and macrophages, respectively (Schnell et al., 1999; Blond et al., 2002). The robust CXCL1 expression observed after both IL- $1 \beta$ and TNF- $\alpha$ in ME7 animals leads to considerable neutrophil infiltration proportionate to the exaggerated CXCL1-expression. TNF- $\alpha$ can induce neutrophil recruitment to the meninges and choroid plexus but these cells failed to infiltrate the parenchyma (Andersson et al., 1992; Campbell et al., 2005). In the current study, this unexpected TNF- $\alpha$-induced CXCL1 production leads to robust neutrophil infiltration, indicating a weakening of regulation of extravasation in the diseased brain. Chemokine expression at the brain endothelium contributes to neutrophil recruitment (Thornton et al., 2010) and many neutrophils were recruited to the glia limitans in NBH + IL- $1 \beta$ animals. However, very few of these extravasated into the tissue compared to ME7 + IL-1 $\beta$, with most remaining at the glia limitans at $24 \mathrm{~h}$ (Fig. $4 g$ ). Thus, the increased neutrophils reaching the parenchyma may be facilitated both by increased numbers recruited but also by their success in extravasating into the tissue. The dramatic neutrophil infiltration observed upon primed microglial responses to LPS in this model (Cunningham et al., 2005) may have been the result of both an exaggerated microglial IL- $1 \beta$ production after LPS challenge and an exaggerated response of astrocytes to that IL-1, producing even more exaggerated CXCL1 secretion and neutrophil recruitment.

At $24 \mathrm{~h}$ TNF- $\alpha$ recruited more CD68-positive cells to the glia limitans of ME7 animals than NBH animals and by $72 \mathrm{~h}$ the TNF- $\alpha$-injected hippocampus showed significantly increased Pu.1-positive labeling, which was blocked by systemic depletion of monocytes using Mc21. Thus, when CCL2 expression is exaggerated, more monocytes are recruited to brain barriers and more also extravasate. Although T-cells were somewhat increased in the hippocampus at $72 \mathrm{~h}$, the large increase in Pu.1-positive cells is the major contributor to the observed hypercellularity in the ME7 + TNF- $\alpha$ hippocampus. There is significant CSF-1/IL-34dependent microglial proliferation in the ME7 model (GómezNicola et al., 2013) and increased Ki67-positive proliferating cells were apparent after TNF- $\alpha$ in the current study. We observed little $\mathrm{Pu} .1 / \mathrm{Ki} 67$ double labeling but cannot exclude the possibility of increased proliferation of microglia. Notwithstanding this, the robust monocyte infiltration indicates clear downstream effects of astrocyte priming and exaggerated CCL2 expression, which may be important for outcomes. Astrocytic NF $\kappa \mathrm{B}$ leads to expression of CCL2 in axonal injury (Khorooshi et al., 2008) and ablation of astrocytic CCL2 reduces CNS accumulation of macrophages, clinical deficits, and axon loss in experimental autoimmune encephalomyelitis (Moreno et al., 2014). CCL2 has also been shown to increase blood-brain barrier permeability by redistributing tight junction proteins (Stamatovic et al., 2006; Yao and Tsirka, 2011). Our data indicate that TNF- $\alpha$ induction of exaggerated CCL2 in the degenerating brain facilitates significant monocyte infiltration and may have significant deleterious consequences.

\section{Conclusion}

Both astrocytes and microglia are primed by chronic neurodegeneration to produce exaggerated responses to IL- $1 \beta$ and TNF- $\alpha$. A generalized heightened inflammatory sensitivity of multiple cell populations in degenerating brain is highly significant, since sterile CNS inflammatory insults such as stroke and traumatic brain injury (TBI) are common in the aging and neurodegenerating brain and exaggerated chemokine and resulting cellular responses could have extremely deleterious consequences for the vulnerable brain. Expression level of CXCL1 and its receptor CXCR2 determine magnitude of neutrophil infiltration, resulting neuronal loss, and infarct volume in TBI and stroke (Semple et al., 2010; Ritter et al., 2011) and limiting neutrophil and CCR2+ macrophage infiltration improves neuropathological and functional outcomes in models of cerebral ischemia, TBI, and repeated concussion (McColl et al., 2008; Shultz et al., 2013; Morganti et al., 2015). Individuals experiencing insults superimposed upon existing neurodegenerative disease may suffer more severe leukocyte recruitment and worse functional outcomes; understanding the mechanisms of these exaggerated responses may provide potential targets for therapeutic intervention.

\section{References}

An Y, Chen Q, Quan N (2011) Interleukin-1 exerts distinct actions on different cell types of the brain in vitro. J Inflamm Res 2011:11-20. Medline Andersson PB, Perry VH, Gordon S (1992) Intracerebral injection of proinflammatory cytokines or leukocyte chemotaxins induces minimal myelomonocytic cell recruitment to the parenchyma of the central nervous system. J Exp Med 176:255-259. CrossRef Medline

Blond D, Campbell SJ, Butchart AG, Perry VH, Anthony DC (2002) Differential induction of interleukin-1beta and tumour necrosis factor-alpha may account for specific patterns of leukocyte recruitment in the brain. Brain Res 958:89-99. CrossRef Medline 
Brambilla R, Bracchi-Ricard V, Hu WH, Frydel B, Bramwell A, Karmally S, Green EJ, Bethea JR (2005) Inhibition of astroglial nuclear factor kap$\mathrm{paB}$ reduces inflammation and improves functional recovery after spinal cord injury. J Exp Med 202:145-156. CrossRef Medline

Brambilla R, Morton PD, Ashbaugh JJ, Karmally S, Lambertsen KL, Bethea JR (2014) Astrocytes play a key role in EAE pathophysiology by orchestrating in the CNS the inflammatory response of resident and peripheral immune cells and by suppressing remyelination. Glia 62:452-467. CrossRef Medline

Bruhl H, Cihak J, Plachý J, Kunz-Schughart L, Niedermeier M, Denzel A, Rodriguez Gomez M, Talke Y, Luckow B, Stangassinger M, Mack M (2007) Targeting of Gr-1+, CCR2 + monocytes in collagen-induced arthritis. Arthritis Rheum 56:2975-2985. CrossRef Medline

Campbell SJ, Wilcockson DC, Butchart AG, Perry VH, Anthony DC (2002) Altered chemokine expression in the spinal cord and brain contributes to differential interleukin-1beta-induced neutrophil recruitment. J Neurochem 83:432-441. CrossRef Medline

Campbell SJ, Perry VH, Pitossi FJ, Butchart AG, Chertoff M, Waters S, Dempster R, Anthony DC (2005) Central nervous system injury triggers hepatic CC and CXC chemokine expression that is associated with leukocyte mobilization and recruitment to both the central nervous system and the liver. Am J Pathol 166:1487-1497. CrossRef Medline

Chen J, Buchanan JB, Sparkman NL, Godbout JP, Freund GG, Johnson RW (2008) Neuroinflammation and disruption in working memory in aged mice after acute stimulation of the peripheral innate immune system. Brain Behav Immun 22:301-311. CrossRef Medline

Choi K, Ni L, Jonakait GM (2011) Fas ligation and tumor necrosis factor alpha activation of murine astrocytes promote heat shock factor-1 activation and heat shock protein expression leading to chemokine induction and cell survival. J Neurochem 116:438-448. CrossRef Medline

Chung IY, Benveniste EN (1990) Tumor necrosis factor-alpha production by astrocytes. Induction by lipopolysaccharide, IFN-gamma, and IL-1 beta. J Immunol 144:2999-3007. Medline

Cunningham C, Wilcockson DC, Campion S, Lunnon K, Perry VH (2005) Central and systemic endotoxin challenges exacerbate the local inflammatory response and increase neuronal death during chronic neurodegeneration. J Neurosci 25:9275-9284. CrossRef Medline

Fouillet A, Mawson J, Suliman O, Sharrack B, Romero IA, Woodroofe MN (2012) CCL2 binding is CCR2 independent in primary adult human astrocytes. Brain Res 1437:115-126. CrossRef Medline

Godbout JP, Chen J, Abraham J, Richwine AF, Berg BM, Kelley KW, Johnson RW (2005) Exaggerated neuroinflammation and sickness behavior in aged mice following activation of the peripheral innate immune system. FASEB J 19:1329-1331. Medline

Gómez-Nicola D, Fransen NL, Suzzi S, Perry VH (2013) Regulation of microglial proliferation during chronic neurodegeneration. J Neurosci 33: 2481-2493. CrossRef Medline

Henn A, Kirner S, Leist M (2011) TLR2 hypersensitivity of astrocytes as functional consequence of previous inflammatory episodes. J Immunol 186:3237-3247. CrossRef Medline

Hughes MM, Field RH, Perry VH, Murray CL, Cunningham C (2010) Microglia in the degenerating brain are capable of phagocytosis of beads and of apoptotic cells, but do not efficiently remove PrPSc, even upon LPS stimulation. Glia 58:2017-2030. CrossRef Medline

Jing T, Wu L, Borgmann K, Surendran S, Ghorpade A, Liu J, Xiong H (2010) Soluble factors from IL-1beta-stimulated astrocytes activate NR1a/NR2B receptors: implications for HIV-1-induced neurodegeneration. Biochem Biophys Res Commun 402:241-246. CrossRef Medline

Khorooshi R, Babcock AA, Owens T (2008) NF-kappaB-driven STAT2 and CCL2 expression in astrocytes in response to brain injury. J Immunol 181:7284-7291. CrossRef Medline

Kim JM, Oh YK, Lee JH, Im DY, Kim YJ, Youn J, Lee CH, Son H, Lee YS, Park JY, Choi IH (2005) Induction of proinflammatory mediators requires activation of the TRAF, NIK, IKK and NF-kappaB signal transduction pathway in astrocytes infected with Escherichia coli. Clin Exp Immunol 140:450-460. CrossRef Medline

Lee YH, Kim SH, Kim Y, Lim Y, Ha K, Shin SY (2012) Inhibitory effect of the antidepressant imipramine on NF-kappaB-dependent CXCL1 expression in TNFalpha-exposed astrocytes. Int Immunopharmacol 12:547-555. CrossRef Medline
McColl BW, Rothwell NJ, Allan SM (2008) Systemic inflammation alters the kinetics of cerebrovascular tight junction disruption after experimental stroke in mice. J Neurosci 28:9451-9462. CrossRef Medline

McKimmie CS, Graham GJ (2010) Astrocytes modulate the chemokine network in a pathogen-specific manner. Biochem Biophys Res Commun 394:1006-1011. CrossRef Medline

Moreno M, Bannerman P, Ma J, Guo F, Miers L, Soulika AM, Pleasure D (2014) Conditional ablation of astroglial CCL2 suppresses CNS accumulation of M1 macrophages and preserves axons in mice with MOG peptide EAE. J Neurosci 34:8175-8185. CrossRef Medline

Morganti JM, Jopson TD, Liu S, Riparip LK, Guandique CK, Gupta N, Ferguson AR, Rosi S (2015) CCR2 antagonism alters brain macrophage polarization and ameliorates cognitive dysfunction induced by traumatic brain injury. J Neurosci 35:748-760. CrossRef Medline

Murray C, Sanderson DJ, Barkus C, Deacon RM, Rawlins JN, Bannerman DM, Cunningham C (2012) Systemic inflammation induces acute working memory deficits in the primed brain: relevance for delirium. Neurobiol Aging 33:603-616.e3. CrossRef Medline

Pace JL, Russell SW, Torres BA, Johnson HM, Gray PW (1983) Recombinant mouse gamma interferon induces the priming step in macrophage activation for tumor cell killing. J Immunol 130:2011-2013. Medline

Pott Godoy MC, Tarelli R, Ferrari CC, Sarchi MI, Pitossi FJ (2008) Central and systemic IL-1 exacerbates neurodegeneration and motor symptoms in a model of Parkinson's disease. Brain 131:1880-1894. CrossRef Medline

Ritter L, Davidson L, Henry M, Davis-Gorman G, Morrison H, Frye JB, Cohen Z, Chandler S, McDonagh P, Funk JL (2011) Exaggerated neutrophil-mediated reperfusion injury after ischemic stroke in a rodent model of type 2 diabetes. Microcirculation 18:552-561. CrossRef Medline

Schnell L, Fearn S, Schwab ME, Perry VH, Anthony DC (1999) Cytokineinduced acute inflammation in the brain and spinal cord. J Neuropathol Exp Neurol 58:245-254. CrossRef Medline

Semple BD, Bye N, Ziebell JM, Morganti-Kossmann MC (2010) Deficiency of the chemokine receptor CXCR2 attenuates neutrophil infiltration and cortical damage following closed head injury. Neurobiol Dis 40:394-403. CrossRef Medline

Shultz SR, Bao F, Weaver LC, Cain DP, Brown A (2013) Treatment with an anti-CD11 d integrin antibody reduces neuroinflammation and improves outcome in a rat model of repeated concussion. J Neuroinflammation 10:26. CrossRef Medline

Sly LM, Krzesicki RF, Brashler JR, Buhl AE, McKinley DD, Carter DB, Chin JE (2001) Endogenous brain cytokine mRNA and inflammatory responses to lipopolysaccharide are elevated in the $\mathrm{Tg} 2576$ transgenic mouse model of Alzheimer's disease. Brain Res Bull 56:581-588. CrossRef Medline

Stamatovic SM, Dimitrijevic OB, Keep RF, Andjelkovic AV (2006) Protein kinase Calpha-RhoA cross-talk in CCL2-induced alterations in brain endothelial permeability. J Biol Chem 281:8379-8388. CrossRef Medline

Thompson WL, Van Eldik LJ (2009) Inflammatory cytokines stimulate the chemokines CCL2/MCP-1 and CCL7/MCP-3 through NFkB and MAPK dependent pathways in rat astrocytes [corrected]. Brain Res 1287:47-57. CrossRef Medline

Thornton P, McColl BW, Greenhalgh A, Denes A, Allan SM, Rothwell NJ (2010) Platelet interleukin-1alpha drives cerebrovascular inflammation. Blood 115:3632-3639. CrossRef Medline

Wang Y, Luo W, Reiser G (2007) The role of calcium in protease-activated receptor-induced secretion of chemokine GRO/CINC-1 in rat brain astrocytes. J Neurochem 103:814-819. CrossRef Medline

Yao Y, Tsirka SE (2011) Truncation of monocyte chemoattractant protein 1 by plasmin promotes blood-brain barrier disruption. J Cell Sci 124:14861495. CrossRef Medline

Yona S, Kim KW, Wolf Y, Mildner A, Varol D, Breker M, Strauss-Ayali D, Viukov S, Guilliams M, Misharin A, Hume DA, Perlman H, Malissen B, Zelzer E, Jung S (2013) Fate mapping reveals origins and dynamics of monocytes and tissue macrophages under homeostasis. Immunity 38 : 79-91. CrossRef Medline

Zamanian JL, Xu L, Foo LC, Nouri N, Zhou L, Giffard RG, Barres BA (2012) Genomic analysis of reactive astrogliosis. J Neurosci 32:6391-6410. CrossRef Medline

Zhang ZJ, Cao DL, Zhang X, Ji RR, Gao YJ (2013) Chemokine contribution to neuropathic pain: respective induction of CXCL1 and CXCR2 in spinal cord astrocytes and neurons. Pain 154:2185-2197. CrossRef Medline 